\title{
TEM study of the austenitic phase of high Ms CuAINi alloys
}

\author{
V. Pelosin, M. Gerland, G. Covarel and A. Rivière \\ Laboratoire de Mécanique et de Physique des Matériaux, ENSMA, BP. 40109, \\ 86961 Futuroscope-Chasseneuil, France
}

\begin{abstract}
CuAINi shape memory alloys, with Ms close to $130^{\circ} \mathrm{C}$ (in the as-quenched state) have been studied on single crystalline and polycrystalline samples.

The specimens have been quenched after heat treatment at $850^{\circ} \mathrm{C}$. The structural study discussed in the present paper has been performed using electrical resistivity and TEM (Transmission Electron Microscopy) analysis. The electron diffraction patterns show that the austenite of the two as-quenched samples is a disordered and body-centred cubic structure. Then, after one annealing at $165^{\circ} \mathrm{C}$ performed in the TEM, the polycrystalline austenite reorders in a facecentred cubic structure ( $\left(\mathrm{L}_{1}\right.$-type), while the single crystalline austenite (annealed at $172{ }^{\circ} \mathrm{C}$ ) stays in the disordered state. Nevertheless, during the heating of the single crystal sample above $A_{F}$, ordered precipitates appear in the parent phase along the former martensite- martensite interface traces.

In addition, precipitates of the $\mathrm{Cu}_{9} \mathrm{Al}_{4}\left(\gamma_{2}\right)$ phase are evidenced in the two samples after annealings below $172{ }^{\circ} \mathrm{C}$.

These observations, the structural difference between the single- and the polycrystalline austenite and the low temperature precipitation of the $\gamma_{2}$ phase, are quite original and have to be discussed by taking into consideration previous investigations performed on similar alloys.
\end{abstract}

\section{INTRODUCTION}

The $\beta$ phase of the CuAlNi alloys is disordered $(\mathrm{A} 2, \operatorname{Im} 3 \mathrm{~m})$ at high temperature, $\mathrm{T}>580{ }^{\circ} \mathrm{C}$, but on cooling, two ordering transformations may take place, first $\mathrm{A} 2 \rightarrow \mathrm{B} 2(\mathrm{Pm} 3 \mathrm{~m})$ then, at lower temperature, $\mathrm{B} 2 \rightarrow \mathrm{L} 2{ }_{1}(\mathrm{Fm} 3 \mathrm{~m})$. If the quenching treatment, that usually allows to obtain the martensitic phase, can hardly suppress the occurrence of the first ordering transition, the B2 order could be retained at low temperature [1]. Nevertheless, by annealing in the austenite phase, it is possible to modify the order degree. Ageing phenomena observed in CuAlNi austenite are commonly described in three more or less independent stages associated with reordering process and precipitation of stable phases [2]. In the first one, typically for an annealing below $200{ }^{\circ} \mathrm{C}$, some authors have observed short range ordering, but the transformation temperatures are not significantly changed [3-4]. The second stage is also associated with ordering phenomena but the gamma $2\left(\gamma_{2}-\mathrm{Cu}_{9} \mathrm{Al}_{4}\right)$ or other rich aluminium phase precipitation could also occur and the transformation temperatures are increased. Finally, in the last stage, the microstructure is decomposed and the martensite transition cannot happen anymore.

In the present work, we have focused the investigations on the microstructural evolution of two $\mathrm{CuAlNi}$ alloys which exhibit, in the as-quenched state, Ms transformation temperatures ranged between $127^{\circ} \mathrm{C}$ and $137^{\circ} \mathrm{C}$. Our main purpose is to study the structural modifications induced in the parent phase during the first stage of ageing, and consequently, the annealing temperatures have been limited to $172^{\circ} \mathrm{C}$.

\section{EXPERIMENTAL PROCEDURE}

Two CuAlNi alloys with close compositions have been studied : first, a singlecrystal elaborated by ORIMI Steel containing $13.6 \% \mathrm{Al}-3.14 \% \mathrm{Ni}(\mathrm{wt} \%)$ and second, a polycrystal provided by Goodfellow with nominal composition $13.3 \% \mathrm{Al}-3.08 \% \mathrm{Ni}$ (wt\%). The quantitative analysis of the elements has been performed by the ICP method (Inductive Coupling Plasma emission).

Both alloys were initially annealed at $850^{\circ} \mathrm{C}$ during 1 hour then water quenched at $20^{\circ} \mathrm{C}$ in order to obtain a martensitic structure at room temperature. Martensitic transformation temperatures were 
measured using a four-point electrical resistivity method during heating and cooling runs performed between $20^{\circ} \mathrm{C}$ and $200^{\circ} \mathrm{C}$ at a rate of $2 \% \mathrm{~min}$.

Disc-type specimens of $3 \mathrm{~mm}$ in diameter have first been cut by spark machining, then mechanically thinned down to about $70 \mu \mathrm{m}$, and finally thin foils have been obtained using the double jet technique with a $66 \%$ methanol and $33 \%$ nitric acid solution operating at $10 \mathrm{~V}$ and $-30{ }^{\circ} \mathrm{C}$. Observations have been performed in a Philips CM20 TEM operating at $200 \mathrm{kV}$, with a Gatan specimen heating holder.

\section{RESULTS}

\subsection{Transformation temperatures}

The determination of the transformation temperatures has been performed during several thermal cyclings up to $200{ }^{\circ} \mathrm{C}$ (anisothermal annealing), then after one isothermal annealing of 24 hours at $200{ }^{\circ} \mathrm{C}$. The results obtained on As and Ms measurements are reported in table 1. One can state that these temperatures are not significantly modified during the anisothermal annealings in the singlecrystal while they are slightly increased in the polycrystal. In addition, in the two samples, the electrical resistivity level measured both in the martensite and in the austenite is not changed during the thermal cycling. On the other hand, in the two samples, the isothermal treatment leads to a marked increase of both Ms and As and to an irreversible decrease of the resistivity level, respectively $6 \%$ for the singlecrystal and $10 \%$ for the polycrystal.

Table 1: Ms and As temperatures, measured by the electrical resistivity method in the two samples during cycling run $\left(2{ }^{\circ} \mathrm{C} / \mathrm{min}\right.$ up to $200^{\circ} \mathrm{C}$ ) and after a 24 hour-treatment at $200^{\circ} \mathrm{C}$.

\begin{tabular}{|l|c|c|c|c|}
\cline { 2 - 5 } \multicolumn{1}{c|}{} & \multicolumn{2}{c|}{$\mathrm{Ms} \pm 3\left({ }^{\circ} \mathrm{C}\right)$} & \multicolumn{2}{c|}{ As $\pm 3\left({ }^{\circ} \mathrm{C}\right)$} \\
\cline { 2 - 5 } \multicolumn{1}{c|}{} & Singlecrystal & Polycrystal & Singlecrystal & Polycrystal \\
\hline First anisothermal annealing & 137 & 127 & 113 & 102 \\
\hline Fourth anisothermal annealing & 138 & 132 & 111 & 108 \\
\hline After 24 hours at $200{ }^{\circ} \mathrm{C}$ & 160 & 151 & 123 & 129 \\
\hline
\end{tabular}

As it will be stated afterwards, these temperatures can be modified on thin samples used for in-situ TEM analysis. In fact, the interest of these results does not concern the absolute value of the temperature but its evolution with ageing treatments.

\subsection{Microstructural observations}

The observations described in the following sections have been performed in the austenitic phase and during the transition. Indeed, the presence of numerous defects as stacking faults, interfaces and so on, in the martensite, makes more difficult the microstructure analysis and could prevent the observation of some structural details.

\subsubsection{Polycrystal}

The sample has been in-situ heated up to $138^{\circ} \mathrm{C}$ in order to make the transformation start. The diffraction pattern obtained in the freshly formed austenite domains can be indexed in a bcc structure with $a_{0}=2.89 \AA$, that corresponds to a disordered austenite, usually called B2 type, space group Pm3m. In addition, one could locally observe a rather high density of small stacking faults in the austenitic matrix.

Then, the sample has been isothermally maintained at $138{ }^{\circ} \mathrm{C}$. As shown in figure 1 , after an annealing of only 20 minutes, small precipitates have formed in some domains of the austenite. The cuboïdal shape of these precipitates is characteristic of the gamma 2 phase $\left(\mathrm{Cu}_{9} \mathrm{Al}_{4}\right)$; usually they are observed in CuAINi alloys only for annealing above $200^{\circ} \mathrm{C}$ [3-5]. In addition, the diffraction pattern taken 
from an array of precipitates shows that the diffraction spots of the precipitates are located at $n \times g / 3$ in one $<110\rangle$ direction of the bcc matrix (figure 1). These results, in addition to further diffraction patterns, indicate that the precipitates have a cubic structure with a cell parameter $\mathrm{ap}_{\mathrm{p}}=8.67 \AA$ and exhibit a strong orientation relationship with the austenitic matrix. From literature, (JCPDS-ICDD data), the $\gamma_{2}$ phase is referenced as a complex cubic structure with a cell parameter of $8.77 \AA$. After 24 hours at $138^{\circ} \mathrm{C}$, the density and size of the precipitates have just locally slightly increased.

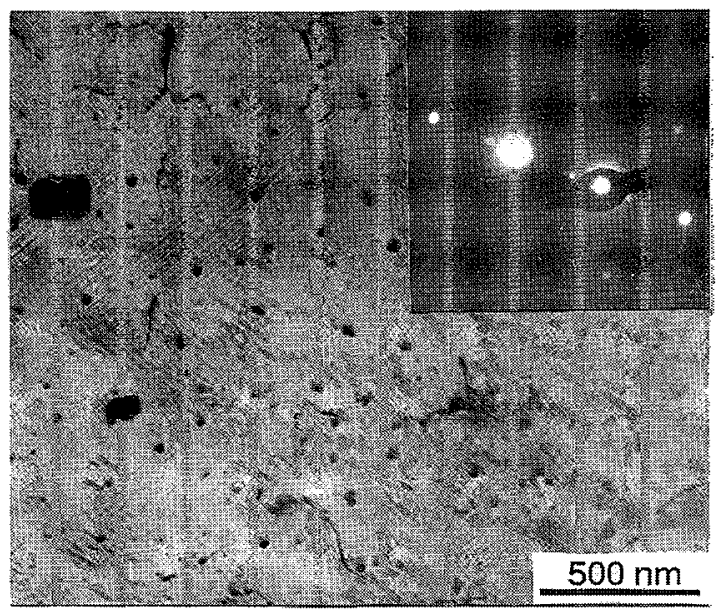

Figure 1: TEM micrograph showing $\gamma_{2}$ precipitates in the polycristalline sample after 20 minutes at $138^{\circ} \mathrm{C}$. Small stacking faults are also visible.

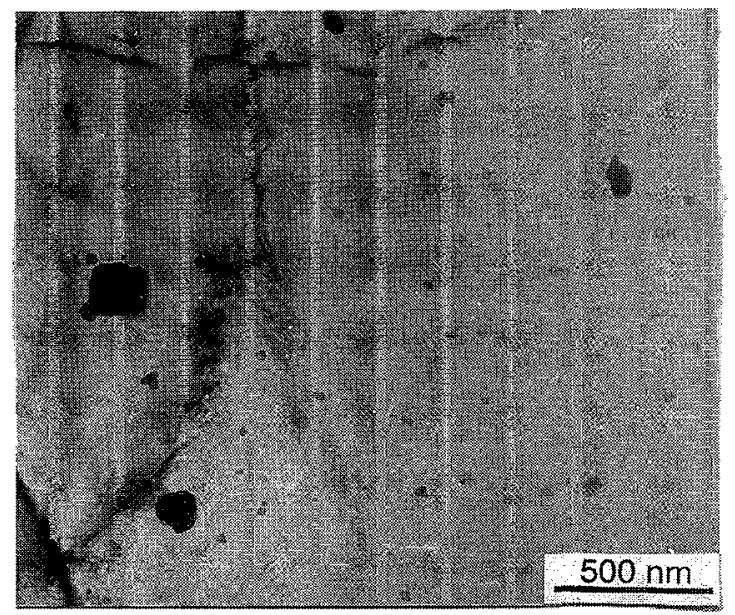

Figure 2: TEM micrograph in the same area as in Fig. 1 after an annealing of 24 hours at $165^{\circ} \mathrm{C}$.

In order to definitively eliminate all the martensite domains, the specimen has been isothermally annealed at $165{ }^{\circ} \mathrm{C}$ during 24 hours, then, the temperature has been decreased down to $120{ }^{\circ} \mathrm{C}$, the temperature at which the first martensite variants begin to appear. As shown in figure 2, taken in the same austenitic domain than that of figure 1, the thermal annealing has had quite no effect since rare precipitates have disappeared while only two or three of them have slightly increased. Nevertheless, the main modification induced by the annealing concerns the austenitic structure that reveals itself as being fcc with $a_{0}=5.81 \AA$. In fact, this structure corresponds to a higher degree of order of the austenite, certainly the $L 2_{1}$ type, space group $\mathrm{Fm} 3 \mathrm{~m}$. Moreover, it can also be noted that the stacking faults observed in the austenite before annealing cannot be evidenced anymore.

\subsubsection{Singlecrystal}

In order to directly observe the austenitic phase, the single crystalline sample has also been heated up to $146^{\circ} \mathrm{C}$ just after having been quenched. The diffraction pattern indicates that the austenitic structure is bcc with $\mathrm{a}_{0}=2.89 \AA$, which corresponds to the $\mathrm{B} 2$ structure, as previously mentioned. The specimen has been submitted to an isothermal annealing at $172{ }^{\circ} \mathrm{C}$ during 24 hours then cooled down to $138{ }^{\circ} \mathrm{C}$. The investigation has concerned many domains of the sample and the first statement was that no $\gamma_{2}$ type precipitate was directly observed. Nevertheless, by working in the reciprocal space, it was possible to weakly highlight spots corresponding to an fcc structure with $a_{p}=8.67 \AA$ and exhibiting the following orientation relationship with the matrix : $(011)_{\mathrm{FCC}} / /(011)_{\mathrm{CC}}$ and $[200]_{\mathrm{FCC}} /[200]_{\mathrm{CC}}$, as shown in figure 3 . 


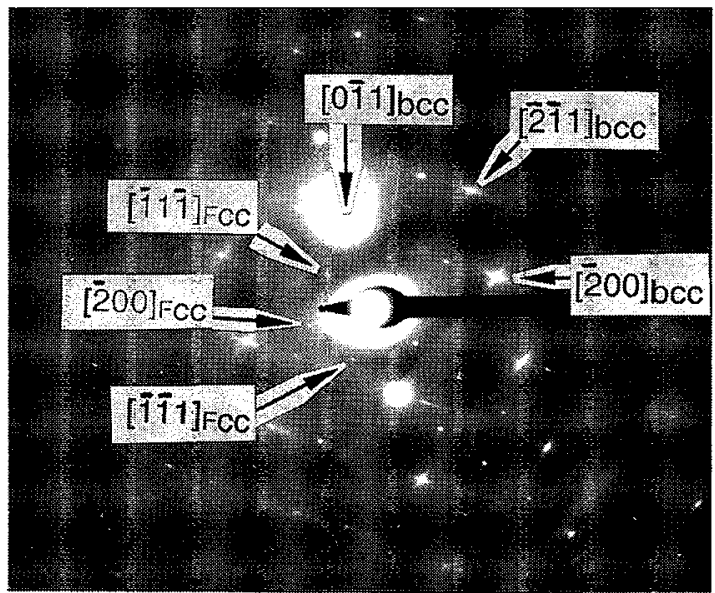

Figure 3: Selected area diffraction pattern of the singlecrystal at $138^{\circ} \mathrm{C}$ after an annealing of 24 hours at $172{ }^{\circ} \mathrm{C}$ showing both bcc and fcc structures.

The second significant result concerns the austenitic structure which has not evolved during the thermal treatment and is still exhibiting a low degree of order (B2- $\mathrm{Pm} 3 \mathrm{~m}$ ). Figure 4 shows that an isothermal annealing during 24 hours at $138^{\circ} \mathrm{C}$ leads to the complete transformation of the structure in martensite. In order to achieve the analysis of the austenite, the temperature has been increased up to $172^{\circ} \mathrm{C}$.

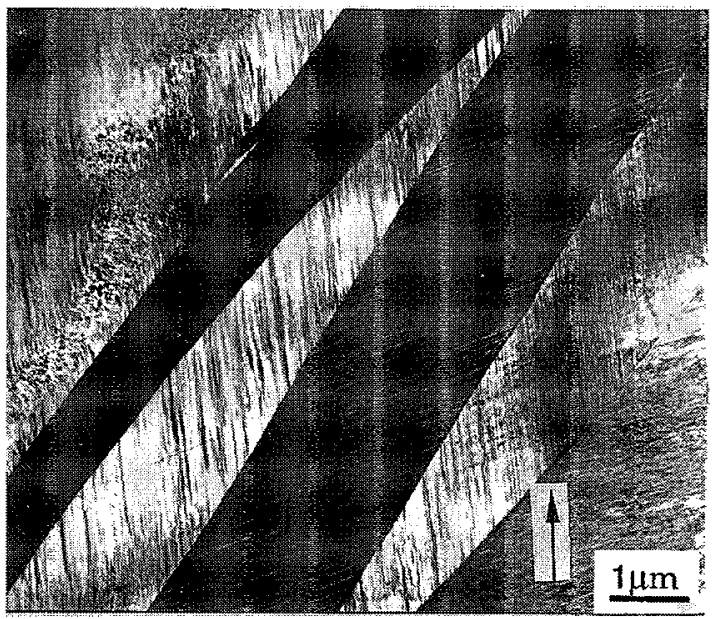

Figure 4: TEM micrograph of the singlecrystal in the martensitic phase at $138^{\circ} \mathrm{C}$.

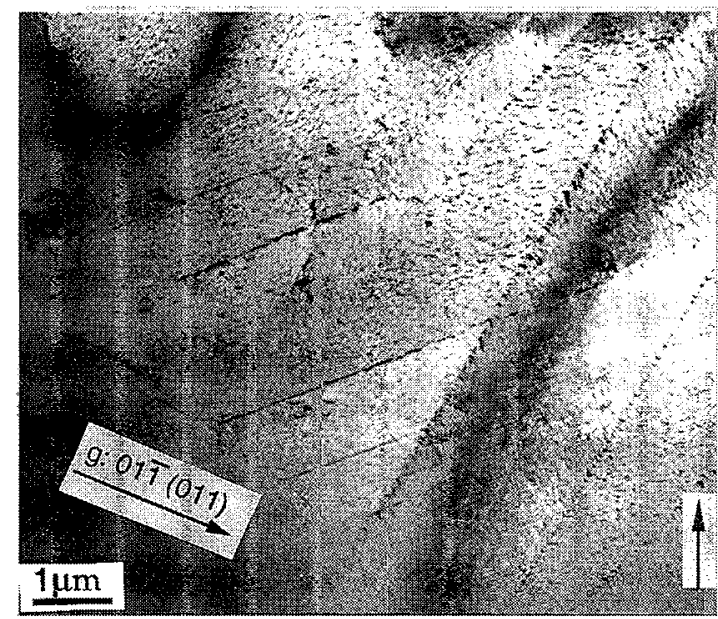

Figure 5: TEM micrograph of the same area as that in figure 4 at $172{ }^{\circ} \mathrm{C}$ in the austenitic phase showing particles along the former interfaces. Arrows indicate the same point in Figures 4 and 5.

As shown in figure 5 , taken in the same area as figure 4 at $138^{\circ} \mathrm{C}$ (the arrows in figures 4 and 5 indicate the same point), fine dark particles are observed straight along the former interfaces between the martensite/martensite variants. The diffraction analysis of these lines indicates that they are composed of precipitates crystallised in an fcc cubic structure with $\mathrm{a}_{0}=5.89 \AA$. In addition, it has been observed that the $<200>$ axes are parallel in both structures. It can be concluded that the bulk disordered austenite has just reordered along specific structural defects such as the former martensite/martensite variants interfaces in 
the present case. Kuwano et al [5] have also observed "small domain of highly ordered phase" but in their CuAlNi alloy they had formed preferentially on antiphase boundary and within the antiphase domains.

\section{DISCUSSION}

The present study shows that important structural modifications such as (short range) ordering and precipitation can be revealed by rather low temperature treatments, $\mathbf{T} \leq 172{ }^{\circ} \mathrm{C}$, in CuAlNi alloys. Nevertheless, the microstructural evolutions are much more substantial in the polycrystal than in the singlecrystal. Indeed, if the as-quenched austenite structure has been found to be bcc disordered in both samples when the temperature is just above As, isothermal annealing at As $+25 / 35^{\circ} \mathrm{C}$ leads to a massive reordering of the cubic structure in the polycrystal, while the same mechanism is only local in the singlecrystal. Moreover, $\gamma_{2}$ precipitation occurs in the polycrystal sample as soon as As is reached and annealing at higher temperature (below $200^{\circ} \mathrm{C}$ ) does not significantly increase the precipitates amount. In the singlecrystal, the precipitation is not clearly evidenced below $172^{\circ} \mathrm{C}$.

One of the main questions raised by these results concerns the dependence and the likely hierarchy existing between the different observed phenomena. In addition, as indicated by the decrease of the electrical resistivity measured during the $200{ }^{\circ} \mathrm{C}$ isothermal treatment, the vacancy elimination must also be taken into account for the discussion.

First, let us consider the polycrystalline sample. It can be stated that both ordering process and vacancy elimination occur at higher temperature (or during a longer annealing) than the $\gamma_{2}$ precipitation. In addition, the transformation temperature increase underlines the fact that the evolution takes place in two independent stages. Indeed, the anisothermal cycles performed up to $200{ }^{\circ} \mathrm{C}\left(2{ }^{\circ} \mathrm{C} / \mathrm{min}\right)$ lead to the complete $\gamma_{2}$ precipitation and correspond to an increase of only $5^{\circ} \mathrm{C}$ and $6{ }^{\circ} \mathrm{C}$ on Ms and As respectively while the same temperatures are risen by $19^{\circ} \mathrm{C}$ and $21^{\circ} \mathrm{C}$ respectively during the isothermal treatment.

Many discussions have already been focused on the origin of the transformation temperature increase $[2-6]$ and the present results clearly show that the main modifications are not induced by the $\gamma_{2}$ precipitation. On the other hand, the sharp rise of As and Ms, similarly observed in the two samples, could be ascribed to the recovery of the second neighbouring order in the austenite phase [6-7].

The fact that the microstructural evolutions are less marked in the singlecrystal, for annealing below $172{ }^{\circ} \mathrm{C}$, is not yet well understood but some hypotheses can be expressed. The resistivity fall being smaller in this sample could indicate that the vacancies are either less numerous either less mobile than in the polycrystal. In any case, this kind of result shows that the vacancy migration process plays a crucial role in the austenite reordering [6-8]. Moreover, the scarce austenite ordered domains being localised at the older martensite/martensite interfaces indicate that these interfaces are preferential zones for the quenched vacancy coalescence. Thus, in the singlecrystal sample, the smaller density of the martensite/martensite interfaces is not sufficient to initiate a bulk structural evolution, in the same thermodynamical conditions than for the polycrystal.

\section{CONCLUSION}

Ageing processes occuring below $200^{\circ} \mathrm{C}$ have been studied in quenched $\mathrm{CuAlNi}$ alloys exhibiting high Ms temperatures. The main results are the following:

1) $\gamma_{2}\left(\mathrm{Cu}_{9} \mathrm{Al}_{4}\right)$ precipitation, as well as ordering process, can be observed for ageing below $172{ }^{\circ} \mathrm{C}$.

2) $\gamma_{2}$ precipitation process precedes ordering and vacancy elimination phenomena. Indeed, the precipitation can occur from only a few minutes after the beginning of the reverse transformation (martensite $\rightarrow$ austenite). Thus, the excess of aluminium of the matrix could be eliminated from the first transformation. 
3) austenite phase ordering, $\mathrm{B} 2(\mathrm{Pm} 3 \mathrm{~m}) \rightarrow \mathrm{L} 2 \mathrm{I}_{\mathrm{I}}(\mathrm{Fm} 3 \mathrm{~m})$, and quenched vacancy elimination seem to be dependent processes as they occur concomitantly. The order transformation starts at the former martensite/martensite interfaces where the vacancies are supposed to have migrated.

4) the temperature transformations are just a little modified by the presence of $\gamma_{2}$ precipitates, while they are significantly increased during the recovery of the second neighbouring order $\left(\mathrm{B} 2 \rightarrow \mathrm{L} 22_{1}\right)$.

\section{Acknowledgments}

The authors are grateful to $\mathrm{M}^{\mathrm{rs}}$ Casseault (University of Orléans) for the ICP analysis.

\section{References}

[1] V. Recarte, O.A. Lambri, R. B. Pérez-Sáez, M.L. Nó and J. San Juan, Appl. Phys. Lett., 70, 26, (1997)

[2] N. Zárubová, A.Gemperle and V. Novák, J de Phys. IV, C5, 281,(1997)

[3] N. Zárubová, A.Gemperle and V. Novák, Mat. Sci. Eng., A222, 166, (1997)

[4] P. Rodriguez and G. Guenin, Mat. Sci. Eng., A129, 273, (1990)

[5] N. Kuwano and C.M. Wayman, Met. Trans. A, 15, 621, (1984)

[6] J. Van Humbeeck, M. Chandrasekaran and L. Delaey, ISIJ Intern., 29, 5, 388, (1989)

[7] Y. Nakata, T. Tadaki and K. Shimizu, Mat. Trans., JIM, 31, 5, 652, (1990)

[8] X. Ren and K. Otsuka, Phase Transitions, 69, 329, (1999) 